Original Article

\title{
Correlation between bright echogenic liver, elevated liver enzymes and liver histology.
}

Dr. Iqbal Murshed Kabir, Dr. Mahbub Alam, Dr. Mohammad Mahmuduzzaman, Dr. Abdullah Al Mamoon, Dr. Mostak Uddin Ahmed, Dr. Syed Alamgir Safwath.

\begin{abstract}
${ }^{I}$ Associate Professor, Department of Gastroenterology (Medicine). Dhaka National Medical College \& Hospital, Dhaka. ${ }^{2}$ Consultant, Department of Gastroenterology, United Hospital Ltd, Gulshan, Dhaka. ${ }^{3}$ Assistant Professor, Department of Gastroenterology Mymenshing Medical College. ${ }^{6}$ Senior Medical Officer, Department of GHPD, Ibrahim Medical College and BIRDEM Hospital. ${ }^{7}$ Assistant Professor, Department of Gastroenterology, Sylhet MAG Osmani Medical College. ${ }^{8}$ Assistant Professor, Department of Gastroenterology, Sylhet MAG Osmani Medical College.
\end{abstract}

\begin{abstract}
A total of 30 cases having bright echogenic liver on ultrasonography and raised ALT levels without Hepatitis $B$ and Hepatitis $C$ infection and without having history of alcohol consumption were referred to Gastroenterology department of BIRDEM Hospital and selected for liver biopsy in the study. The patient's BMI and demographic profiles were recorded and necessary biochemical tests were carried out. After obtaining the histopathological reports, the correlation between different possible risk factors including biochemical findings and histological findings was sorted out. Based on BMI of Asian population, $73.4 \%$ of patients were over weight, $23.3 \%$ were obese and only $3.3 \%$ were with normal BMI. $90 \%$ patients presented with diabetes and $80 \%$ had some form of dyslipidaemia. $41 \%$ patients exhibited hypertriglycerdaemia, $21 \%$ had hypercholesterolaemia and both cholesterol and triglyceride were high in $34 \%$ patients. Histopathological study revealed that all 30 patients exhibited fatty change with macrovesicular type being the predominant. $43.3 \%$ patients had mild (<33\%) steatosis and the rest $56.7 \%$ had moderate (33-66\%) steatosis. In terms of staging of fibrosis in the liver, $83.3 \%$ exhibited stage-1 fibrosis and only $6.7 \%$ had stage-2 fibrosis. The rest $10 \%$ of the patients did not have any fibrosis. No correlation was established between hepatic enzyme levels (AST \& ALT levels) and grading of steatosis \& stage of fibrosis. Study of association between possible risk factors (Age, Sex, Diabetes Mellitus, Dyslipidaemia \& BMI) and grading of steatosis and stage of fibrosis demonstrated that none of these risk factors was associated with those histological findings. Therefore it can be concluded that the patients presenting with bright echogenic liver on ultrasonography and elevated liver enzymes without having hepatitis $B$ and hepatitis $C$ infection and history of alcohol consumption are almost certainly to have Nonalcoholic fatty liver disease (NAFLD) specially if they are diabetic, dyslipidaemic and overweight or obese.The level of liver enzymes and the possible risk factors like age, sex, diabetes mellitus, dyslipidaemia and BMI do not seem to be good estimates of the severity of NAFLD.
\end{abstract}

Keywords: Bright Echogenic Liver, Liver Histology, Elevated Liver Enzymes, Diabetes Mellitus, Dyslipaedemia, BMI.

Introduction

NAFLD could possibly be a part of a metabolic syndrome associated with insulin resistance, diabetes, obesity and hypertension. Patients typically present with asymptomatic serum aminotransferase elevation of 2-3 times the normal (1).

Correspondence:

Dr. Iqbal Murshed Kabir, Associate Professor, Department of Gastroenterology (Medicine). Dhaka National Medical College \& Hospital, 53/1, Johnson Road, Dhaka - 1100 .
Liver Biopsy is useful and effective as a prognostic indicator, but it is an invasive and costly tool to diagnose fatty liver (2). Hyperechogenic (bright) liver indicates steatosis by ultrasonography (3).

The prevalence of overweight and obesity is increasing in Bangladesh especially in females due to a change in dietary habits and a sedentary life style. In clinical practice, we frequently encounter bright echogenic liver on ultrasonography in Bangladesh. Many of those patients have elevated liver enzymes especially ALT. 
Probably the ultimate diagnosis of those patients is NASH if we exclude alcohol consumption and HBV, HCV infections. But no study has yet been conducted in Bangladesh to determine the ultimate histological diagnosis of those patients. Moreover correlation between demographic and biochemical aspect and histopathologic aspect of the disease has not been studied. Liver biopsy, which is an invasive and expensive procedure and which many patients want to avoid is needed to have histopathological confirmation of NAFLD. Therefore, our aim of study is to determine the histological diagnosis of the patients presenting with bright echogenic liver and elevated liver enzymes and to find the correlation among the different aspects of the disease.

\section{Aims and objectives}

1. To determine the histopathological diagnosis of the patients with bright echogenic liver and elevated liver enzymes suspected to have NAFLD.

2. To find correlation between possible risk factors including liver enzymes and findings of liver histology in those patients

\section{Materials and Methods}

This is a cross sectional, purposive, type of study performed in Bangladesh Institute of Research and Rehabilitation in Diabetes, Endocrine and Metabolic Disorders (BIRDEM), Dhaka during the period of June 2005 to December 2006.

The patients presenting with bright echogenic liver on ultrasonography and raised ALT were included in the study. But the patients with hepatitis B and hepatitis C infection, history of alcohol consumption, having history of using steatogenic medications and with serious comorbid disease like significant cardiac, respiratory and renal disease were excluded from the study.

Patients fulfilling the inclusion and exclusion criteria were referred to Gastroenterology department of BIRDEM and selected for liver biopsy in the study. For collection of data a predesigned data collection form was used. Demographic variables like age, sex, height, weight, BMI were recorded. Among the biochemical variables, fasting and $2 \mathrm{hrs}$ after breakfast blood sugar, ALT, AST, Alkaline phosphatase, Sr. bilirubin, Sr. cholesterol, Sr. triglyceride test were carried out. Platelet count and Prothrombin time were measured to assess the fitness for liver biopsy. After obtaining the histopathological report, the correlation between different possible risk factors including biochemical findings and histopathological findings was sorted out.

BMI was calculated by the Quetlet index, i.e., weight in $\mathrm{kg} /\left(\right.$ height in $\mathrm{m}^{2}$ ). Obesity, overweight and lean status were defined by a BMI of more than 27.5 $\mathrm{kg} / \mathrm{m} 2,23-27.4 \mathrm{~kg} / \mathrm{m} 2$ and less than $23 \mathrm{~kg} / \mathrm{m} 2$, respectively, for Asians (4). Fatty liver was diagnosed by ultrasonography using an ATL HDI 5000 abdominal probe. Longtiudinal, subcostal, ascending, and oblique scans were performed. Liver biopsy was performed in all patients using True-cut biopsy needle under local anaesthesia. Histology sections were stained with Hematoxylline-Eosin stain. All biopsies were carefully staged and graded by an experienced pathologist. The histologic grade ( a score of $0-3$, derived from the degree of steatosis, hepatocyte ballooning, lobular and portal inflammation ) and the stage of fibrosis (0-4) were scored using the classification as described by modified Brunt et al (5).

The study protocol was approved by the Medical Ethics Committee of BIRDEM Academy. Informed consent was obtained from the patients informing the explanations of all procedures, consequence of the study and complication of liver biopsy.

Data were analysed using SPSS (Statistical Package for Social Sciences) version 11.5. For each analytical test the level of significance was set at 0.05 and p < 0.05 was considered significant.

\section{Result}

A total of 30 cases, ultrasonographically diagnosed as bright echogenic liver with elevated liver enzymes and having no history of alcohol consumption, were enrolled in the study to find their histopathlogical diagnosis, grading of steatosis and staging of fibrosis. The study was also aimed at assessing the association between possible risk factors and histologic findings.

\section{Age distribution of patients}

Age distribution of the patients shows that $43.3 \%$ were in between $30-40$ years of age followed by $20 \%$ between $50-60$ years, $18.3 \%$ between $40-50$ years, $6.7 \% 60$ or above 60 years and only $1(3.3 \%)<30$ years of age. The mean age was $42.4 \pm 8.9$ years. (Table I).

Table I. Age distribution of patients $(n=30)$

\begin{tabular}{ccc}
\hline Age (yrs) \# & No & Percentage \\
\hline$<30$ & 01 & 3.3 \\
$30-40$ & 13 & 43.3 \\
$40-50$ & 08 & 18.3 \\
$50-60$ & 06 & 20.0 \\
$>>60$ & 02 & 6.7 \\
\hline
\end{tabular}

$\#$ Mean $=(42.4 \pm 8.9)$ years; range $=(25-65)$ years.

\section{Sex distribution:}

Fig. 1 demonstrates that out of 30 cases selected for study, 15 were males and 15 females giving a malefemale ratio of $1: 1$. 


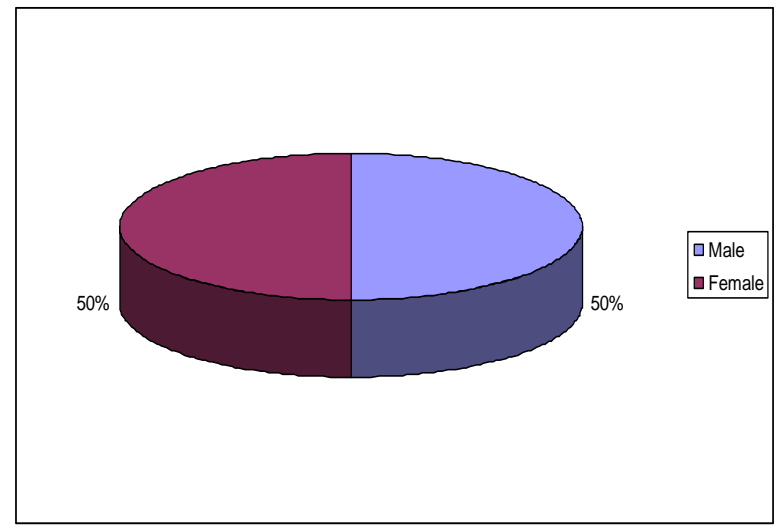

Fig. 1: Distribution of the patients by $\operatorname{sex}(n=30)$

\section{BMI:}

Based on BMI of Asian population, the obesity status of the patients was defined. Nearly three-quarter (73.4\%) of the patients were over-weight, $23.3 \%$ obese and only $1(3.3 \%)$ was with normal BMI. The mean BMI was $26.02 \pm 2.46 \mathrm{~kg} / \mathrm{m}^{2}$. (Table II).

Table II. Distribution of patients by obesity status ${ }^{\#}$ $(\mathbf{n}=30)$

\begin{tabular}{lcc}
\hline \multicolumn{1}{c}{ BMI* $\left(\mathbf{k g} / \mathbf{m}^{2}\right)$} & No & \\
\hline$<23 \mathrm{~kg} / \mathrm{m}^{2}$ (Normal) & 01 & 3.3 \\
$23-27.5 \mathrm{~kg} / \mathrm{m}^{2}$ (Over-weight) & 22 & 73.4 \\
$>27.5 \mathrm{~kg} / \mathrm{m} 2$ (Obese) & 07 & 23.3 \\
\hline
\end{tabular}

$*$ Mean $=(26.02 \pm 2.46) \mathrm{kg} / \mathrm{m}^{2} ;$ range $=(20.8-33.5)$ $\mathrm{kg} / \mathrm{m}^{2}$.

\# Obesity status was defined according to BMI of Asian population (13)

\section{Presence of risk factors:}

Out 30 cases $27(90 \%)$ patients presented with diabetes and $24(80 \%)$ had some form of dyslipidemia (serum cholesterol $>200 \mathrm{mg} / \mathrm{dl}$ and triglyceride $>150 \mathrm{mg} / \mathrm{dl}$ )) as revealed on investigation of lipid profile (Fig.2).

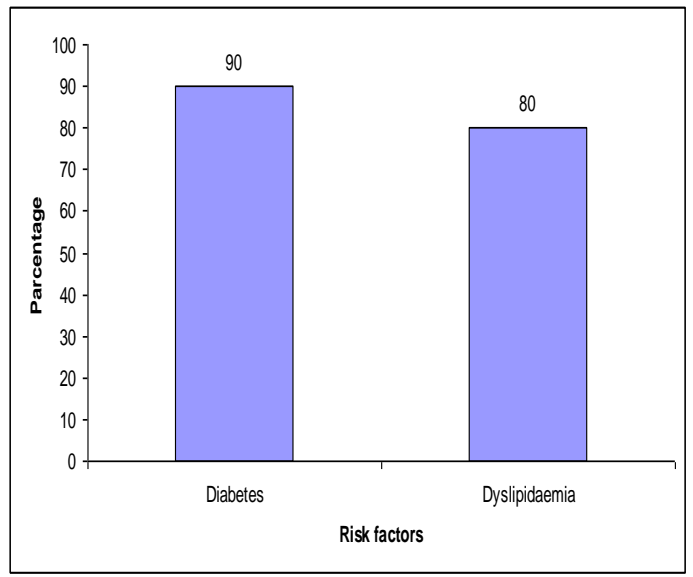

Fig. 2: Distribution of patients by risk factors $n=$ 30)

\section{Type of dyslipidemia:}

Of the 24 patients who had dyslipidaemia, 10(41\%) exhibited triglyceride > $150 \mathrm{mg} / \mathrm{dl}, 5(21 \%)$ had cholesterol > $200 \mathrm{mg} / \mathrm{dl}$ and both cholesterol and triglyceride were high in $9(38 \%)$ patients.

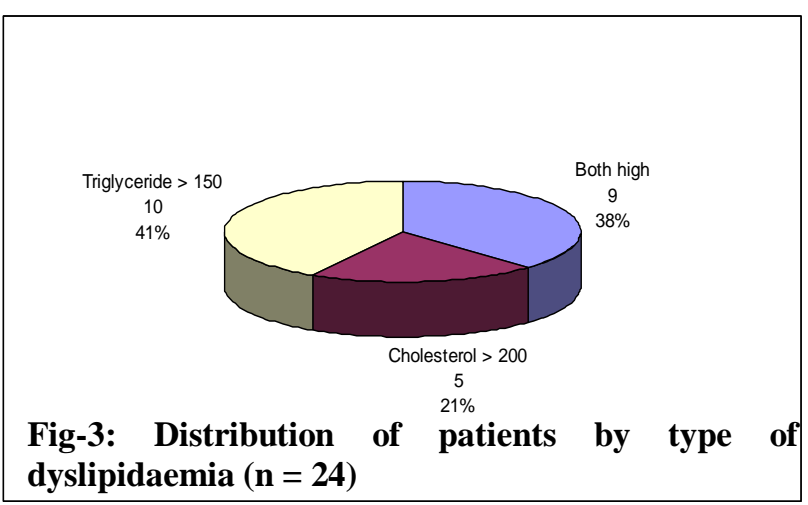

Steatosis and associated inflammation:

Histological study revealed that $43.3 \%$ patients had mild $(<33 \%)$ steatosis and the rest $56.7 \%$ had moderate $(33-66 \%)$ steatosis. All the 30 patients exhibited fatty change with macrovesicular type being the predominant. Mild degree of lobular and portal inflammation was found in $86.7 \%$ and $80 \%$ of the cases respectively, while moderate degree of the same inflammations was found in $10 \%$ and $16.7 \%$ respectively. Only $1(3.3 \%)$ case was free from either inflammation (Table III).

Table III. Steatosis and associated inflammation in histologic study $(n=30)$

\begin{tabular}{lcc}
\hline \multicolumn{1}{c}{ Steatotic variables } & No & $\begin{array}{l}\text { Percentag } \\
\text { e }\end{array}$ \\
\hline $\begin{array}{l}\text { Percentage of steatosis: } \\
<33 \text { (mild) }\end{array}$ & 13 & 43.3 \\
33 - 66 (moderate) & 17 & 56.7 \\
$\begin{array}{l}\text { Type of steatosis: } \\
\text { Predominantly macrovesicular }\end{array}$ & 30 & 100.0
\end{tabular}

Ballooning degeneration:

Present

Absent

01

Lobular inflammation

01

Absent

Mild

Moderate

Portal inflammation

Absent 
Grade 3 (Severe steatohepatitis)

Staging of fibrosis $(0-4)$

Stage 0 (No fibrosis)

Stage 1 (Mild fibrosis)

Stage 2 (Moderate fibrosis)

$02 \quad 6.7$

Stage 3 (Bridging fibrosis)

$00 \quad 0.0$

Biochemical characteristics of the patients

Table IV shows the mean level of some biochemical

Stage 4 (Liver cirrhosis)

$00 \quad 0.0$ variables related to NASH. The mean level of alanine aminotransferase (ALT) was $105.57 \pm 34.15 \mathrm{IU} / \mathrm{L}$ and that of aspartate aminotransferase (AST) was $55.53 \pm$ 25.58. The AST to ALT ratio was $0.53 \pm 0.17$. The mean serum cholesterol $(211.17 \pm 70.63 \mathrm{mg} / \mathrm{dl})$ and triglyceride $(216.37 \pm 111.79 \mathrm{mg} / \mathrm{dl})$ levels were both higher than upper limit of normal range.

Table IV. Some important biochemical features of NASH patients $(n=30)$

\begin{tabular}{|c|c|c|c|}
\hline Parameters & \multicolumn{2}{|c|}{ Mean \pm SD } & Range \\
\hline$\overline{\mathrm{ALT}}(\mathrm{IU} / \mathrm{L})$ & 105.57 & \pm 34.15 & $54-220$ \\
\hline AST (IU/L) & 55.53 & \pm 25.58 & $23-137$ \\
\hline AST/ALT & 0.53 & \pm 0.17 & $0.29-0.99$ \\
\hline $\begin{array}{l}\text { Alkaline phosphatase } \\
\text { (IU/L) }\end{array}$ & 107.83 & \pm 44.55 & $56-276$ \\
\hline $\begin{array}{l}\text { Serum } \\
(\mathrm{mg} / \mathrm{dl})\end{array}$ & 0.64 & +0.38 & $0.4-1.7$ \\
\hline Cholesterol (mg/dl) & 211.17 & -70.63 & $126-498$ \\
\hline Triglyceride $(\mathrm{mg} / \mathrm{dl})$ & & 1.79 & $94-601$ \\
\hline
\end{tabular}

\section{Histological evaluations:}

Histological evaluation based on Modified Brunt's classification demonstrates that nearly half $(46.7 \%)$ of the patients had mild steatohepatitis (Grade-1) and the rest $53.3 \%$ had moderate steatohepatitis (Grade-2). None had severe degree of steatohepatitis. In terms of staging of fibrosis in the liver, majority $(83.3 \%)$ exhibited stage 1 fibrosis and only $6.7 \%$ had stage 2 fibrosis. The rest $3(10 \%)$ of the patients did not have any fibrosis (Table V).

Table V. Histological evaluations according to Modified Brunt's classification $(n=30)$ :

\begin{tabular}{lcc}
\hline \multicolumn{1}{c}{ Parameters } & Number & Percentage \\
\hline Grading of steatosis (0 - 3) & 00 & 0.0 \\
Grade 0 (Steatosis only) & & \\
Grade 1 (Mild steatihepatitis) & 14 & 46.7 \\
Grade 2 (Moderate & 16 & 53.3 \\
steatohepatitis) & 00 & 0.0
\end{tabular}

\section{Association between grading of steatosis and possible risk factors}

Association between grading of steatosis and possible risk factors like age, sex, diabetes, dyslipidaemia and obesity status (in terms of BMI) demonstrates that none of these factors was associated with grading of steatosis $(\mathrm{p}>0.05)$.

(Table VI). Table VI. Association between grading of steatosis and suspected risk factors

\begin{tabular}{|c|c|c|c|}
\hline \multicolumn{3}{|c|}{ Grading of steatosis } & \multirow[b]{2}{*}{ p-values } \\
\hline $\begin{array}{l}\text { Suspected } \\
\text { factors* }\end{array}$ & $\begin{array}{l}\text { Grade } 1 \\
(n=14)\end{array}$ & $\begin{array}{l}\text { Grade } 2 \\
(n=16)\end{array}$ & \\
\hline $\begin{array}{l}\text { Age }(\text { yrs }) \\
<40\end{array}$ & $7(50.0)$ & $9(56.3)$ & 0.509 \\
\hline$>40$ & $7(50.0)$ & $7(43.7)$ & \\
\hline Sex Male & $6(42.9)$ & $9(56.3)$ & 0.358 \\
\hline Female & $8(57.1)$ & $7(43.7)$ & \\
\hline Diabetes Present & 13(92.9) & $14(87.5)$ & 0.552 \\
\hline Absent & $1(7.1)$ & $2(12.5)$ & \\
\hline $\begin{array}{l}\text { Dyslipidaemia } \\
\text { Present }\end{array}$ & $10(71.4)$ & $14(87.5)$ & 0.261 \\
\hline Absent & $4(28.6)$ & $2(12.5)$ & \\
\hline $\begin{array}{l}\text { BMI }(\mathrm{kg} / \mathrm{M} 2) \\
<27.5 \text { (Normal \& }\end{array}$ & $10(71.4)$ & $13(81.3)$ & 0.419 \\
\hline > 27.5 (Obese) & $4(28.6)$ & $3(18.7)$ & \\
\hline
\end{tabular}

Data were analysed using Fisher's Exact Test; level of significance was 0.05 .

\section{Association between staging of fibrosis and possible risk factors:}

Table VII compares the distribution of possible risk factors among different stages of fibrosis. None of the risk factors was prone to be associated with staging of fibrosis $(\mathrm{p}>0.05)$ (Table VII). 
Table VII. Association between staging of fibrosis and suspected risk factors

Staging of fibrosis

*p-values

\begin{tabular}{lcccc}
$\begin{array}{c}\text { Suspected risk } \\
\text { factors* }\end{array}$ & $\begin{array}{c}\text { Stage 0 } \\
(\mathbf{n = 3})\end{array}$ & $\begin{array}{c}\text { Stage 1 } \\
(\mathbf{n = 2 5})\end{array}$ & $\begin{array}{c}\text { Stage 2 } \\
(\mathbf{n = 2})\end{array}$ & \\
\hline Age $(\mathrm{yrs})<40$ & $2(66.7)$ & $12(48.0)$ & $2(100.0)$ & 0.325 \\
$>40$ & $1(33.3)$ & $13(52.0)$ & 0.0 & \\
Sex Male & $1(33.3)$ & $13(52.0)$ & $1(50.0)$ & 0.830 \\
Female & $2(66.7)$ & $12(48.0)$ & $1(50.0)$ & \\
Diabetes Present & $3(100.0)$ & $22(88.0)$ & 0.0 & 0.717 \\
Absent & $0.0)$ & $3(12.0)$ & $2(100.0)$ & \\
$\begin{array}{l}\text { Dyslipidaemia } \\
\text { Present }\end{array}$ & $2(66.7)$ & $20(80.0)$ & $2(100.0)$ & 0.659 \\
Absent & $1(33.3)$ & $5(20.0)$ & 0.0 & \\
$\begin{array}{l}\text { BMI (kg /M2) } \\
\text { < 27.5 (Normal }\end{array}$ & $2(66.7)$ & $20(80.0)$ & $1(50.0)$ & 0.572 \\
$\begin{array}{l}\text { \& overweight.) } \\
>27.5 \text { (Obese) }\end{array}$ & $1(33.3)$ & $5(20.0)$ & $1(50.0)$ & \\
\hline
\end{tabular}

Data were analysed using Chi-square $\left(\mathrm{x}^{2}\right)$ Test; level of significance was 0.05 .

\section{Discussion}

NAFLD is now recognized as the most common liver disease in the west (6). It is probably the third common reason for referral to specialist in Gastroenterology and Hepatology $(7,8)$. At the same time, Diabetes mellitus and obesity, two closely associated diseases, have been shown to be rapidly increasing in prevalence (9). In outpatient clinics of Bangladesh, we encounter many patients having bright echogenic liver on ultrasonography and elevated liver enzymes, specially who are diabetic and dyslipidaemic. If hepatitis B and hepatitis C infection and history of alcohol consumption are excluded, these patients are presumed to have NAFLD. As other forms of chronic liver disease specially Autoimmune hepatitis and Heamochromatosis are rare in our country and socioeconomic status of the population is low, we did not go for investigations to exclude these diseases.
As histopathological examination reveals the confirmed diagnosis of NAFLD, we performed liver biopsy of all our patients. All of our patients had steatohepatitis; $53 \%$ having moderate and $46.7 \%$ having mild steatohepatitis. This is a remarkable finding and is probably due to precise patient selection in our study, exclusion of cases with normal transaminase levels or positive markers of viral hepatitis. Moreover, most of our patients were diabetic (90\%), dyslipidaemic $(80 \%)$, overweight $(73.4 \%)$ and obese (23.3\%), which are established risk factors for NAFLD. As NAFLD is ultimately a histological diagnosis, a wider study in a random population in the community could tell us whether a combination of LFTs and ultrasound of liver examination will allow us to detect patients with NASH without having to perform a liver biopsy.

Consistent with the published literatures, we found that almost all of our patients (96.7\%) were either overweight $(73.4 \%)$ or, obese $(23.3 \%)$ with a mean BMI of 26.02 .

Insulin resistance has been noted to be crucial in the pathogenesis of NAFLD and obesity has been reported to play a major role in insulin resistance (10-12). So naturally majority of our patients had frank diabetes mellitus (90\%). We observed some form of dyslipidaemia in $80 \%$ of our patients. Others have reported similar prevalences $(13,14)$. These biochemical and metabolic derangements point to the fact that NAFLD is primarily a metabolic disorder and is widely considered as a component of the metabolic syndrome which carries with it an increased risk of cardiovascular and cerebrovascular diseases (15).

Liver enzyme levels in our patients were similar to previous reports (16). The mean ALT level was 105.57 and mean AST level was 55.53. The AST/ALT ratio was below 1 in all patients and mean AST/ALT ratio was 0.53 which is a characteristic and important finding in NAFLD (17).

Histological examination of the study population showed a broad spectrum of abnormalities that have been reported with NAFLD. Factors affecting the pathogenesis of NAFLD are steatosis, inflammation and fibrosis (18-20). $43.3 \%$ of our patients has mild steatosis while $56.7 \%$ had moderate steatosis which are similar to other reports. $96.7 \%$ o of the patients had ballooning degeneration, lobular inflammation and portal inflammation. NAFLD can cause fibrosis and progress to cirrhosis. Alarmingly, $90 \%$ of the study population had mild $(83.3 \%)$ to moderate $(6.7 \%)$ fibrosis on histology even though they were clinically asymptomatic..

We attempted to find the correlation of liver enzymes and possible risk factors like BMI, Diabetes mellitus and dyslipidaemia with the histological findings. The findings on liver biopsy were not correlated to liver enzymes and other risk factors. Thus the liver enzymes 
and risk factors do not seem to be good estimates of the severity of liver disease. However, further largescale prospective study is required to find more precise correlation among different aspects of NAFLD.

While our patients do not necessarily represent the whole population of NAFLD, we feel that our study provides an important insight into the spectrum of the disease encountered clinically, bearing in mind the feasibility and difficulty in persuading otherwise asymptomatic patients to undergo liver biopsy. Our findings further emphasize the importance of NAFLD and the need to diagnose it before it causes irreversible liver damage.

\section{Bibliography}

1. Marceau P,Biron S, Hould FS, Marceau S, Simard S, Thung SN,et al. Liver pathology and the metabolic syndrome $\mathrm{X}$ in severe obesity. J Clin Endocrinol Metab 1999;84:1513-7.

2. Joy, Diamond, Thava, Vallipuram R, Scott \& Brain B.Diagnosis of fatty liver disease; is biopsy necessary? Eur J Gastroenterol Hepatol 2003;15;539-43.

3. Joseph AEA, Dewlbury KC, McGuire PG. Ultrasound in the detection of chronic liver disease(the "bright" liver) $\mathrm{Br} \mathrm{J}$ Radiol 1979;57:23-7.

4. WHO expert consultation. Appropriate bodymass index for Asian populations and its implications for policy and intervention strategiens. Lancet 2004; 363: 157-63.

5. Semin Liver Dis 24(1):3-20,2004. 2004 Thieme Medical Publishers

6. Adams IA, Lymp JF, St Sauver J, Sanderson SO. The natural history of nonalcoholic fatty liver disease: a population-based cohort study. Gastroenterology 2005; 129: 113-21.

7. Willner IR, Waters B, Raj Patil S. ninety patients with nn-alcoholic steatohepatitis: insulin resistance, familiar tendency and severity of disease 2001; 96 (10):2957-61.

8. Byron D, Minuk GY. Profile of an urban hospital -based practice. Hematology 1996; 24:813-815.

9. Chitturi S, Ferrell GC, George J. Nonalcoholic steatohepatitis in the Asia-Pacific region; Future shock? J Gastroenterol Hepatol 2004; 19:368-74.

10. Cortez-Pinto H, Camilo ME, Baptista A, De Oliveira AG, De Moura MC. Nonalcoholic fatty liver: another feature of the metabolic syndrome? Clin Nutr 1999; 18: 353-358.

11. Marchesini G, Brizi M, Morselli- Labate AM, Bianchi G, Bugianesi E, Mc Cullough AJ et al. Association of nonalcoholic fatty liver disease with insulin resistance. Am J Med 1999; 107: 450-455.

12. Chitturi S, Abeygunasekera S, Farrell GC, Holmes-Walker J, Hui JM, Fung $\mathrm{C}$ et al. $\mathrm{NASH}$ and insulin resistance: insulin hypersecretion and specific association with the insulin resistance syndrome. Hepatology 2002; 35: 373-379.

13. Diehl AM, Goodman Z, Ishak KG. AlcoholLike liver disease in nonalcoholics. A clinical and histologic comparison with alcoholinduced lover injury. Gastroenterology 1988;95:1056-1062.

14. Pinto HC, Baptista A, Camilo ME, Valente A, Saragoca, de Moura MC et al. Non-alcoholic steatohepatitis. Clinicopathological comparison with alcoholic hepatitis in ambulatory and hospitalized patients. Dig Dis Sci 1996;41:172.

15. Report of the Obesity, Metabolic Syndrome and Hypertension Writing Group. Discovering the full spectrum of Cardiovascular disease, Minority Health Summit 2003. Circulation 2005;111;e134-9.

16. N. Ebrahimi Daryani, Sh . Mirmomen, H. Bahrami et al. Clinical and histologicalfeatures of nonalcoholic steatohepatitis in Iranian patients. Acta Medica Iranica, 41(1);50-54:2003.

17. SorbiD, Boynton J, Lindor KD. The ratio of aspartate aminotransferase to alanine minotransferase: potential value in differentiating nonalcoholic steatohepatitis from alcoholic liver disease. Am J Gastroenterol 1999;94:1018-1022.

18. Acosta D, Werizel DG. Injury produced by free fatty acids to lysosomes and mitochondria in cultured heart muscle and endothelial cells . Atherosclerosis 1974;20:417.

19. Dianzani MU. Hepatotoxicology. In: Biochemical aspects of fatty liver, Meeks RG, Harrison SD, Bull RJ (Eds) CRC, Boca Raton 1991;p:327.

20. Lombardi B. Fatty liver : Considerations on the pathogenesis of fatty liver. Lab Invest 1966; 15:1. 